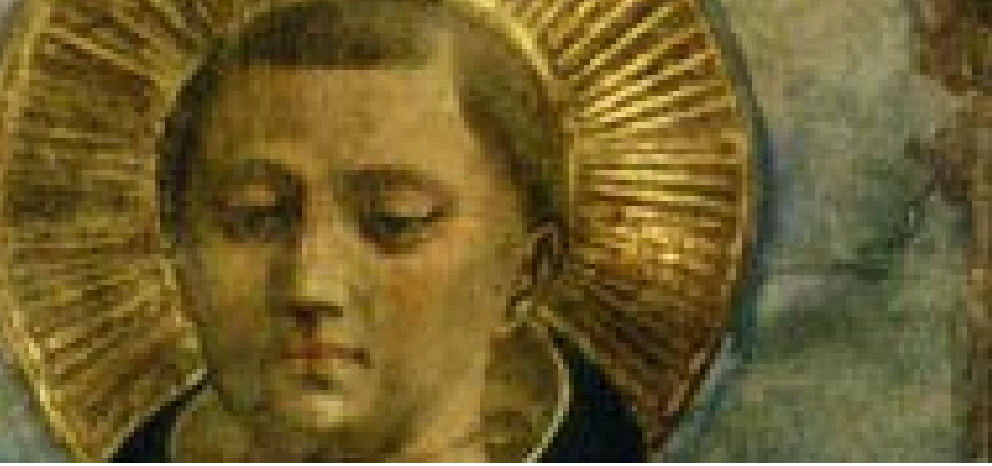

\section{Divergencias respecto a la noción de esclavitud aristotélica en el pensamiento de Santo Tomás de Aquino}

\author{
Divergences regarding the notion of Aristotelian slavery in the thought of Saint \\ Thomas Aquinas
}

\section{Resumen}

El presente trabajo pretende abordar la noción de esclavitud aristotélica a través del pensamiento de Santo Tomás de Aquino, donde se busca primeramente precisar las consideraciones centrales del tema en cuestión, para luego converger ambas interpretaciones, si bien, reconocemos que existen numerosas divergencias respecto del término, puesto que, en estricto rigor, Tomás de Aquino considera principalmente la noción de servidumbre por sobre la noción de esclavitud, es menester propiciar un orden para luego abordar y diferenciar ambas nociones contrapuestas. Posteriormente se buscará interpolar la esclavitud o servidumbre frente a la libertad y derechos inalienables de la persona humana, como también abordar la problemática referida a la dignidad, ya que aceptar la esclavitud o servidumbre implicaría generar un dilema de carácter antropológico-moral.

\section{Palabras clave}

Divergencias, noción, esclavitud, Aristóteles, Santo Tomás de Aquino.

\begin{abstract}
The present work aims to address the notion of Aristotelian slavery through the thought of St. Thomas Aquinas, which seeks primarily to clarify the central considerations of the subject in question, then converge both interpretations, although, we recognize that there are many divergences regarding the term Since, strictly speaking, Thomas Aquinas considers mainly the notion of servitude over the notion of slavery, it is necessary to propitiate an order to then approach and differentiate both opposing notions. Later, it will be sought to interpolate slavery or servitude in the face of the inalienable freedom and rights of the human person, as well as to address the problems related to dignity, since accepting slavery or servitude would imply generating a moral-anthropological dilemma.
\end{abstract}

\section{Keywords}

Divergences, notion, slavery, Aristotle, Saint Thomas Aquinas

Recepción de artículo: 5-7-2018

Aceptación del artículo: 25-11-2018

\section{BORIS OSVALDO SAAVEDRA PÉREZ Universidad Santo Tomás, Chile. Universidad San Sebastián, Chile.}

Licenciado en Filosofía, Universidad Católica de la Santísima Concepción. Actualmente se desempeña como docente e investigador de la Universidad Santo Tomás, impartiendo las asignaturas de: Cultura y Valores, Persona y Sentido y Ética Profesional. También se desempeña como docente en la Universidad San Sebastián impartiendo las asignaturas de Dilemas Morales y Filosóficos del Siglo $X X I$, Antropología y Ética: el Bien, la Verdad y la Belleza.

\section{Últimas publicaciones realizadas:}

"Contraposición e implicancias respecto a la noción de concordia política aristotélica como principio operativo del Estado en la mediación de los conflictos según la perspectiva de Santo Tomás de Aquino", en Revista de Filosofía de la Universidad Católica de la Santísima Concepción, (ISS 0717-7801), vol. $16, n^{\circ} 2,2017$, pp. 23-38.

\section{ORCID 曲}




\section{PRESUPUESTO DE LA NOCIÓN ESCLAVISTA ARISTOTÉLICA}

Para establecer una adecuada comprensión de la esclavitud ${ }^{1}$ en el pensamiento del Estagirita primeramente se debe considerar su fundamento político a la luz de la concepción natural que le otorga a la polis, en efecto, la polis se encuentra estrechamente relacionada con la physis y el concepto de telos, puesto que Aristóteles ve una finalidad natural y no meramente convencional, nómos, en la formación de la comunidad, ya que la naturaleza social del hombre, zoon politikon, será la causante de las múltiples agrupaciones que se dan en la vida humana ${ }^{2}$. Siendo la primera agrupación importante la familia, esto dará pie a la formación posterior de la aldea, ${ }^{3}$ que logrará la protección y resguardo de los distintos hogares que componen la comunidad, de ahí que, la aldea será necesaria para la subsistencia humana, permitiendo llevar a cabo los diferentes procesos de socialización y ayuda frente a las distintas necesidades que se darán en la comunidad. Aunque, el Filósofo no precisa cuáles son los deberes exactos de la aldea, si se deja entrever en su teoría política, que se refiere a las consideraciones relativas a la vida perfecta, esto es, la ordenación moral adecuada al Bien Común, ya que de esta manera se tiene una incidencia directa en la vida práctica del hombre, el ethos, o, la vida moral. Efectivamente, en el Corpus aristotelicum la vida doméstica, (lo que usualmente se denominaba como: Oikos, oikia, y que daba lugar a la oikonomía) ${ }^{4}$, será el núcleo primario y central de la polis, puesto que la conjunción de cada hogar atiende a una relación analógica que se presenta de manera pública y que además posee una dimensión eminentemente social, siendo su finalidad principal, precisamente, la aspiración al Bien Común. Ahora bien, Aristóteles no solamente comprenderá un supuesto natural en la formación del Estado, sino que, además, atendiendo a su finalidad introducirá una orientación relativa a la virtud de la justicia. Según señala el Estagirita: 'Todas las constituciones políticas son una especie de justicia, pues son comunidades, y todo lo común se funda en la justicia. Por consiguiente, hay tantas especies de amistad como de justicia y de comunidad; y todas estas especies lindan unas con otras y tienen diferencias apenas perceptibles' ${ }^{\prime 5}$. Por lo tanto, existe una proporcionalidad analógica fundada y entendida por medio de la relación específica que la justicia genera. De igual manera, se advierte que la finalidad de agruparse atiende también a un instinto natural, tal como lo señala Ross: 'Hay dos instintos primarios que llevan a los seres humanos a asociarse entre sí: el instinto de reproducción, que reúne al hombre y la mujer, y el instinto de conservación, que reúne al amo y al —al espíritu providente y al cuerpo vigoroso- para prestarse ayuda mutua. ${ }^{6}$ De este modo, notamos la perfecta relación que Aristóteles le confiere al Estado como un conjunto natural ${ }^{7}$ que se encuentra compuesto del núcleo central propiciado por la familia, seguido de la aldea, y la comunidad. De ahí que, el Estado se convierta en: 'la comunidad de comunidades $^{\prime 8}$, ya que esto le confiere su importancia primigenia y vital para comprender cabalmente el rol de la relación familiar dentro de la comunidad, y de la misma manera, la relación que cada miembro de la familia posee entre sí, evidentemente, el padre ejerce dominio sobre la familia, y a su vez, esto implica una administración adecuada del oikos, por lo tanto, la mujer y los hijos estarán gobernados por el padre, pero igualmente el esclavo será gobernado por el amo, ya que esto atiende a una relación analógica. En efecto, según precisa Aristóteles: 'A su vez, la relación entre el señor y el esclavo es la del arte y los instrumentos, del alma y el cuerpo, relaciones que no son amistades ni formas de justicia, sino algo análogo, como tampoco la salud no es justicia, sino algo análogo'9. Por lo tanto, se deja en claro la importancia que posee cada miembro de la comunidad para que el Estado logre su finalidad.

\section{NOCIÓN DE ESCLAVITUD ARISTOTÉLICA}

Aristóteles no cuestiona la institución de la esclavitud, ya que era algo común en Atenas $^{10}$, más bien, pareciera ser que pretende justificarla como algo necesario para la correcta administración de la casa, según afirma: 'las partes de la administración doméstica corresponden a aquellas de que constan a su vez la casa, y la casa perfecta la integran esclavos y libres'11. Por lo tanto, en primera instancia, la esclavitud es esencial dentro de la polis, más aún, cuando el Estagirita la concibe como un supuesto natural, según señala: 'Mandar y obedecer no sólo son cosas necesarias, sino también convenientes, y ya desde el nacimiento algunos están destinados a obedecer y otros a mandar'12. De acuerdo con esto, la principal característica que diferencia a unos hombres de otros será la posesión de la libertad, ya que, en estricto rigor, el hombre que goza de libertad será radicalmente diferente al que no la posee, esto es, el esclavo por naturaleza. Aún así, se debe entender que ambos participan de la misma naturaleza, en efecto, según plantea Martínez: 'El Estagirita no trata del esclavo como de una naturaleza diferente, el esclavo no es otra especie del género "animal" distinta del hombre, sino un hombre, cuya naturaleza es la de esclavo'13 En este sentido, resulta paradójico que, aunque el hombre libre y el esclavo pertenezcan a la misma naturaleza exista una diferenciación morfológica entre sus cuerpos, en efecto, para Aristóteles la propia naturaleza se encargará

1. Cf. Capizzi 2002, p. 32

2. Cf. Reale 1985, pp. 113-114; Cf. MOREAU 1972, pp. 220-221.

3. Cf. Ross 1957, p. 289.

4. Cf. Mirón 2004, pp. 61-79.

5. Aristóteles, Ética Eudemia, Libro VII, 1241b, 15.

6. Cf. Ross 1957, p.282.

7. 'Aristóteles contribuyó grandemente a la filosofía política sosteniendo que el Estado no existe simplemente por convención, sino que tiene sus raíces en la naturaleza humana; que el Estado natural, en el sentido más verdadero, debe buscarse, no en los orígenes de la vida humana, sino en la meta hacia la cual tiende; que la vida civilizada no es un estado de decadencia con relación a la vida de un salvaje hipotéticamente noble; que el Estado no es una restricción artificial de la libertad, sino un medio de lograrla'. Ross 1957, p. 283

8. Ibid., p. 283.

9. Aristóteles, Ética Eudemia, Libro VII, 1242a, 30

10. García 2008, p. 156.

11. Aristóteles, Política, Libro I, 1253b, 3.

12. Aristóteles, Política, Libro I, 1254a, 2.

13. Martínez 2001, p.91. 
de dotar con mayor vigor y fuerza física el cuerpo del esclavo para que pueda ejecutar las diferentes tareas que le serán encomendadas por el amo, sin embargo, cabe advertir que dicha diferenciación morfológica no será exclusiva del hombre, ya que Aristóteles también le atribuye tal distinción a la naturaleza animal, de ahí que, existan animales que se encuentran distantes de otros, según lo explica el Estagirita:

Así pues, todos los seres que se diferencian de los demás tanto como el alma del cuerpo y como el hombre del animal (se encuentran en esta relación todos cuantos su trabajo es el uso del cuerpo, y esto es lo mejor de ellos), estos son esclavos por naturaleza, para los cuales es mejor estar sometidos a esta clase de mando, como en los casos mencionados. Pues es esclavo por naturaleza el que puede ser de otro (por eso precisamente es de otro) y el que participa de la razón tanto como para percibirla, pero no para poseerla; pues los demás animales no se dan cuenta de la razón, sino que obedecen a sus instintos. En la utilidad la diferencia es pequeña: la ayuda con su cuerpo a las necesidades de la vida se da en ambos, en los esclavos y en los animales domésticos ${ }^{14}$

En consecuencia, podemos inferir tres cualidades fundamentales del esclavo por naturaleza: En primer lugar, su pertenencia a otro, ya que al encontrarse en una condición natural de inferioridad con respecto al hombre libre necesita ser gobernado y dirigido por otro mejor, evidentemente, según afirma Leal: 'Aristóteles considera que la unión amo-esclavo es natural porque ciertamente el que tiene la inteligencia previsora es amo, mientras que el que tiene un cuerpo capaz de ejecutar lo previsto es esclavo por naturaleza'15. De este modo, se infiere que la mayor virtud del esclavo es someterse a los requerimientos del amo ya que así podrá establecer la consecución final de su telos, puesto que al pertenecer y ser parte del amo logrará perfeccionarse. Por lo tanto, comprendemos que la teoría de la esclavitud aristotélica no sólo tiene un sustento casuístico, sino que también teleológico.

En segundo lugar, el factor principal de la separación entre el hombre libre y el esclavo se da por el logos no avezado de este último, según lo menciona Mauri:

La posesión plena de la facultad racional supone la posibilidad real de ejercer todas las actividades racionales, mientras que la mera participación no niega la racionalidad, pero limita su ejercicio. Las diferencias naturales entre individuos de la misma naturaleza son uno de los factores que, según Aristóteles, determinan la bondad moral. Tanto en la Política como en Ética Nicomáquea, el autor se refiere a la necesidad de poseer cierta clase de naturaleza como condición para la bondad ${ }^{16}$

En efecto, esto provocaría que el esclavo carezca de una correcta facultad deliberativa, boleutikón, de ahí que, no pueda participar en la política, ya que carece del dominio necesario para poder decidir sobre los asuntos concernientes a la polis, por eso afirma Aristóteles: 'La naturaleza quiere incluso hacer diferentes los cuerpos de los libres y los de los esclavos: unos, fuertes para los trabajos necesarios; otros, erguidos e inútiles para tales menesteres, pero útiles para la vida política'17. Evidentemente, ya que los asuntos de la vida política serán propios de los ciudadanos, aunque tal como señala Ariza: 'El sino de la esclavitud, por tanto, no se refiere a una marca física -puesto que algunos libres tienen los mismos rasgos corporales-, se remite más al plano del alma intelectiva y al ejercicio político, ya que mientras algunos pueden ejercer la razón y ser ciudadanos, otros no, por lo que su mayor provecho es el uso del cuerpo para el trabajo'18.

Y, por último, por el esclavo, serán diversas, permitiendo generar una cierta clasificación en orden a la acción que se realiza, efectivamente, según señala Ross: 'Pero el esclavo es un instrumento, no de producción sino de acción, no para fabricar tal o cual artículo particular, sino para ayudar en la conducción general de la vida. Es decir, que aquí se trata del esclavo doméstico más bien que del esclavo agricultor o industrial'19. Ahora bien, el alcance mencionado por Ross radica en que para Aristóteles existirán algunas tareas que tendrán cierta similitud con la esclavitud, en efecto, las tareas ejecutadas por los campesinos, los obreros y los comerciantes les impedirían preocuparse por los asuntos más elevados, esto es, lo referente a la vida política, por ello, según precisa el Estagirita: 'los ciudadanos no deben llevar una vida de trabajador manual, ni de mercader (pues esa forma de vida es innoble y contraria a la virtud), ni tampoco deben ser agricultores los que han de ser ciudadanos (pues se necesita ocio para el nacimiento de la virtud y para las actividades políticas)' 20 , debido a esto, todos ellos quedarán excluidos de la Eudaimonia, puesto que como nos ilustra Brun: 'Para Aristóteles, como, por otra parte, para los griegos en general, el trabajo manual es una especie de tarea degradante, pues el que a ella se dedica está enteramente absorbido por su labor y su ganancia. Es, pues, indigno de hombres libres ejercer un trabajo de artesano, comerciante o agricultor' . ${ }^{21}$ Por lo tanto, comprendemos porque se mencionan tales actividades como símiles de la esclavitud, o bien, sean consideradas como actividades degradantes en cuanto a su oficio.

Ahora bien, es menester considerar que también existirán esclavos por alguna convención, esto es, respecto de las leyes, como es el caso de los prisioneros de guerra, tal como señala Aristóteles: 'hay también una especie de esclavos y de esclavitud, en virtud de una ley, y esa ley es un cierto acuerdo, según el cual las conquistas de guerra son de los vencedores'22. Por consiguiente, esto será objeto de la justicia, ya que evidentemente, debe obedecerse a los acuerdos que hayan sido prescritos en orden a las leyes que rigen la comunidad, en este caso, los acuerdos legales referentes a los prisioneros de guerra, según afirma Mauri: 'Por una parte, que hay hombres que pierden su libertad cuando son capturados por aquellos que, en razón de la fuerza, los dominan; estos son los esclavos por convención. Por otra parte, Aristóteles también constata que hay hombres incapaces de tomar decisiones certeras sobre

14. Aristóteles, Política, Libro I, 1254b, 8-9

15. Leal 2007, p. 15

16. Mauri 2016, p. 167

17. Aristóteles, Política, Libro I, 1254b, 10

18. Ariza 2005, p. 145

19. Ross 1957, p.285

20. Aristóteles, Política, Libro VII, 1328b, 4

21. Brun 1988, p.129

22. Aristóteles, Política, Libro I, 1255a, 6 
la orientación de su vida; a estos les llama esclavos por naturaleza'23.

Finalmente, cabe advertir que los esclavos serán necesarios dentro de la polis debido a su funcionalidad, puesto que se vuelven imprescindibles para la correcta administración de las posesiones del amo, por lo tanto, si bien el esclavo presta su servicio en sumisión, igualmente puede decidir de manera limitada ciertas implicancias relativas a las funciones que debe ejecutar, ya que también posee racionalidad ${ }^{24}$, (aunque no tan ejercitada como el caso de los hombres libres, según se ha dicho anteriormente) y, además, es superior, en este aspecto, a los animales irracionales, o a los seres inertes, ya que, aunque es considerado inferior al hombre libre, seguirá siendo hombre, por ello Aristóteles afirma:

De los instrumentos, unos son inanimados y otros animados; por ejemplo, para un piloto, el timón es inanimado, y animado el vigía (pues en las artes el subordinado hace las veces de un instrumento). Así también, las posesiones son un instrumento para la vida y la propiedad es una multitud de instrumentos; también el esclavo es una posesión animada, y todo subordinado es como un instrumento previo a los otros instrumentos. ${ }^{25}$

Por ello, la diferencia primordial del esclavo con respecto a los instrumentos inanimados subyace en que el esclavo posee alma, émpsijon, por lo tanto, sería una posesión con alma, clasificado dentro de los instrumentos de acción y distinto de los instrumentos de producción, según precisa nuevamente el Estagirita:

Ahora bien, los llamados instrumentos lo son producción, más las posesiones son instrumentos de acción. En efecto, la lanzadera produce algo aparte de su empleo, pero el vestido y el lecho, sólo su uso. Además, ya que la producción y la acción difieren específicamente, y ambas necesitan de instrumentos, necesariamente éstos deben mantener la misma diferencia. La vida es acción, no producción, y por ello el esclavo es un subordinado para la acción ${ }^{26}$.

En consecuencia, se genera una diferenciación relevante entre la actividad productiva, poiesis, y la acción, praxis, de ahí que, convenga destacar que el esclavo en sentido aristotélico no goza de una condición tan perjudicial como se podría pensar, más bien, se convierte en una pieza clave para el adecuado desarrollo de la administración familiar, por ello, no se le compara con un objeto inanimado, sino más bien, vendría siendo parte del amo, tal como si fuera uno de sus miembros ${ }^{27}$. Sin embargo, a pesar de lo mencionado, el esclavo debe ejecutar con cierto grado de prudencia las tareas asignadas por el amo ya que su posición es inferior debido a su condición. Aún así, es interesante tener en cuenta que al amo se le exige no abusar de su autoridad ${ }^{28}$, puesto que en definitiva el esclavo es hombre, y como tal, merece un trato justo, efectivamente, según señala García: 'El esclavo tenía cierta protección legislativa y religiosa. Si era muerto por su señor, éste debía pagar cuentas en el tribunal de homicidios. Y aquel esclavo que escapase y bajo determinadas circunstancias se refugiase en un templo, no podía ser desalojado y debía ser vendido a precio de saldo'29. De acuerdo con esto, no se busca deslegitimar la condición de los esclavos, al contrario, ellos son necesarios debido a que son esenciales para la economía, de ahí que, se busque generar una cierta "amistad", según plantea Aristóteles: 'Por eso también hay un interés común y amistad recíproca entre esclavo y amo, que merecen serlo por naturaleza. Entre los que no se da tal relación, sino que lo son por convención y forzados, sucede lo contrario. ${ }^{30}$ Ahora bien, dicha amistad, no es en sentido estricto, evidentemente, ya que en la Ética Nicomáquea afirma Aristóteles: 'Tampoco hay amistad hacia un caballo o un buey, o hacia un esclavo en cuanto esclavo, porque nada hay común a estas dos partes; pues el esclavo es un instrumento animado, y el instrumento un esclavo inanimado. ${ }^{31}$ En definitiva, no podría existir amistad entre el amo y el esclavo debido a la desigualdad que se genera entre ambos, esto es, en base a la superioridad que posee el amo con respecto al esclavo, sin embargo, si puede existir una amistad en segundo grado, en tanto que el esclavo es hombre.

Por lo tanto, se concluye de manera general que la esclavitud aristotélica trata de ser justificada desde una concepción ontológica, antropológica, política y ética, estableciéndose un carácter de necesidad primaria y esencial para el adecuado desempeño de la vida en comunidad y alejándose considerablemente de la concepción esclavista planteada por los romanos, o bien, en su defecto, a la interpretación posterior que se da en la modernidad ${ }^{32}$.

\section{CONSIDERACIÓN TOMISTA RESPECTO A LA NOCIÓN DE ESCLAVITUD}

Luego de haber dilucidado de manera general la concepción esclavista de Aristóteles, es menester advertir que en la Edad Media se produce un cambio de paradigma cultural y social, debido principalmente a la influencia ejercida por el cristianismo, en efecto, aunque la esclavitud sigue vigente será reemplazada mayormente por la servidumbre, lo que implica numerosas similitudes y divergencias al respecto. De ahí que, Santo Tomás de Aquino tratará la servidumbre en algunas de sus obras, tales como: Summa Theologiae, Sententia libri Ethicorum, y Sententia Libri Politicorum ${ }^{33}$. Ahora bien, el Doctor Angélico también abordará la servidumbre en otros de sus escritos, pero para efectos

23. Mauri 2016, p.163

24. Cf. Leal 2007, pp. 18-19

25. Aristóteles, Política, Libro I, 1253b, 2

26. Aristóteles, Política, Libro I, 1254a, 4-5

27. Cf. Moreau 1972, p.234

28. Cf. Ross 1957, p.286

29. García 2008, p.152

30. Aristóteles, Política, Libro I, 1255b, 10

31. Aristóteles, Ética a Nicómaco, Libro VIII, 1161 b

32. 'Se debe notar que la esclavitud entre los griegos estaba en gran parte libre de los abusos que la han deshonrado entre los romanos y frecuentemente también en los tiempos modernos'. ROSS 1957, p. 286

33. Cabe señalar que el Comentario a la Política de Aristóteles corresponde a una de las obras póstumas de Santo Tomás, por lo tanto, no contiene en estricto rigor su pensamiento político, Cf. Manser 1947, p. 25 
prácticos nos remitiremos principalmente al primero y segundo antes citado, prescindiendo de la polémica suscitada en torno a la Sententia Libri Politicorum, ya que fue una obra inconclusa terminada por su discípulo Pedro de Alvernia ${ }^{34}$.

Pues bien, siguiendo el planteamiento aristotélico del Estado y sus divisiones, Santo Tomás concluye al igual que el Estagirita la disposición natural que subyace en el hombre para asociarse y perseguir el bien ${ }^{35}$, por lo tanto, será una inclinación natural el agruparse en diversas comunidades, empero su división será propia de la justicia ${ }^{36}$, ya que es la virtud que permitirá regir y ordenar la vida social. Al respecto nos dice Copleston: 'Así, pues, el gobierno debe existir para preservar la paz interna y para procurar la defensa de la comunidad, para promover el bienestar de los ciudadanos, en la medida en que esto puede ser hecho por una legislación apoyada en sanciones, y para asegurarles una satisfacción suficiente de sus necesidades materiales' ${ }^{\prime 37}$. Efectivamente, el Estado deberá contribuir a la persecución del Bien Común y al ordenamiento moral del hombre ${ }^{38}$, de ahí que, el ser humano solamente alcance su plena realización dentro de la comunidad política.

Ahora bien, la problemática referente a la servidumbre será abordada desde tres aspectos fundamentales, según afirma el propio Santo Tomas:

Trabajo servil viene de servidumbre. Pero hay tres clases de servidumbre. Una, cuando el hombre sirve al pecado, conforme al dicho de San Juan $(8,34)$ : El que comete pecado es siervo del pecado. Si lo entendemos así, toda obra pecaminosa es servil. Otra clase de servidumbre es cuando un hombre sirve a otro hombre. Pero un hombre es siervo de otro no en cuanto al alma, sino en cuanto al cuerpo, como quedó anteriormente dicho (q.104 a.5; a.6 ad. 1). En este sentido, los trabajos serviles se denominan corporales. La tercera clase es el servicio a Dios. En este caso podría llamarse trabajo servil a las obras de religión, porque miran al servicio de $\operatorname{Dios}^{39}$.

Para comprender adecuadamente la clasificación de la servidumbre descrita por el Aquinate en la Summa Theologiae, conviene atender a lo siguiente:

En la primera clase de servidumbre, esto es, cuando el hombre sirve al pecado, se infiere una connotación estrictamente teológico-moral, diferente a la interpretación de la esclavitud aristotélica, puesto que Santo Tomás pretende abordar una cierta dimensión evangélica al atribuir esta clase de servidumbre a los hombres que practican el mal, y en su defecto, se vuelven esclavos de los vicios ${ }^{40}$. De ahí que, la soteriología cristiana sostenga el sacrificio expiatorio de Cristo mediante su gracia infinita para redimir a la naturaleza caída del hombre. Por lo tanto, notamos que en este primer aspecto existe una divergencia relevante con respecto a la noción de esclavitud aristotélica.
En la segunda clase de servidumbre, esto es, cuando un hombre sirve a otro hombre, se puede establecer una mayor similitud a la concepción esclavista de Aristóteles, puesto que, la noción de servidumbre adquiere una dimensión social o de carácter política, sobre todo en la labor servil que ejecuta el siervo, en efecto, pareciera ser que Santo Tomás no difiere demasiado del pensamiento del Estagirita en este punto, pero aquello tampoco le otorga una aceptación unívoca, evidentemente, más aún, cuando se comprende que el Aquinate se preocupa mayormente por la problemática referente al Dominium que por la esencia misma de la servidumbre.

Finalmente, en la tercera clase de servidumbre, esto es, el servicio a Dios el Aquinate la considera como un oficio estrictamente religioso que recibe el nombre de latría, y que tiene por objeto la adoración y el culto a Dios. Por lo tanto, es propio de la religión ordenar al hombre con Dios, en efecto, gracias a ello, el hombre le rinde honor, adoración y alabanza a su Creador, de ahí que, la religión sea un servicio especial del hombre a Dios, según afirma Santo Tomás: 'Y también, según parece, forma parte de la religión el culto de latría. Pero latría significa servidumbre, como dice San Agustín en el X De Civ. Dei; y debemos servir no sólo a Dios, sino también al prójimo, según aquello del Apóstol, Gál 5,13: Servíos los unos a los otros por caridad. Luego la religión importa también orden al prójimo'41. Evidentemente, el servicio religioso es un tipo de servidumbre especial, ya que el hombre que ejerce tal tipo de servidumbre se ha consagrado de manera voluntaria a Dios, según dice el Doctor Angélico:

Ahora bien: es evidente que el señorío le pertenece a Dios por una razón propia y singular, a saber: por ser El quien hizo todas las cosas y por tener el principado supremo sobre todo lo creado. Por tanto, se le debe especial servidumbre, y a tal servidumbre en griego se la designa con el nombre de latría. De donde se sigue que, hablando con propiedad, pertenece a la religión.

Por lo tanto, en este tipo de servidumbre también se genera una distinción notoria con la noción de esclavitud Aristotélica, debido a que, "el servicio a Dios" es un supuesto relativo a la fe cristiana ${ }^{42}$.

En consecuencia, se infiere que de las tres clases de servidumbre mencionadas por Santo Tomás podemos establecer un claro paralelismo con la segunda clasificación, esto es, cuando un hombre sirve a otro hombre, efectivamente, la problemática radica en que Tomás de Aquino no parece pronunciarse en contra de la esclavitud, sino más bien, prefiere continuar con la tradición aceptada hasta el momento. Así lo plantea Martínez: 'Es muy poco lo que los padres latinos, por ejemplo, tenían que decir en contra de la esclavitud. La oposición a la doctrina aristotélica se da más bien, como hemos dicho, respecto de su carácter supuestamente natural, pues eso implicaría que Dios habría creado dos naturalezas humanas, una destinada a mandar despóticamente, y otra

34. Cf. Neira 2005, pp. 7-18

35. Cf. Fraile 1975, p.471

36. Cf. Gilson 1978, p.537

37. Copleston 2014, p.302, Cf. Tomás de Aquino Sum. Theol., I-llae, q.94, a. 2., co.

38. Copleston 2014, pp. 302-303

39. Tomás de Aquino, Sum. Theol., II-llae, q.122, a. 4., ad 3.

40. Cf. Rassam 1980, p.282

41. Tomás de Aquino, Sum. Theol., II-Ilae, q.81, a.1, arg.3

42. Tomás de Aquino, Sum. Theol., II-Ilae, q.81, a.1, ad.3 
destinada a la esclavitud' ${ }^{\prime 43}$

De ahí que, el Doctor Angélico se refiera al estado de inocencia para buscar esclarecer la naturaleza de la servidumbre, puesto que originalmente la naturaleza humana no estaba dominada por el pecado, y el Dominium ${ }^{44}$ era entendido desde otra perspectiva totalmente diferente, según afirma el Aquinate:

El dominio tiene doble acepción. 1) Una, como opuesto a la servidumbre; y en este sentido domina quien tiene un siervo. 2)Otra, referida a cualquier modo de tener a alguien sometido; y en este sentido domina quien tiene el gobierno o dirección de personas libres. El dominio en el primer sentido no se daba en el estado de inocencia; mientras que el segundo ciertamente era posible. El porqué de esto radica en que el siervo y el libre difieren en que el libre es dueño de sí, como dice el Filósofo al comienzo de Metaphys.; mientras que el siervo depende de otros. Hay, por tanto, servidumbre cuando se retiene a alguien para utilidad propia. Porque todos desean el bien propio y se entristecen cuando lo propio debe ser cedido en favor de otro, este dominio conlleva la aflicción en los sometidos. Por eso no podía darse en el estado de inocencia. ${ }^{45}$

De acuerdo con esto, el Dominium es fruto de la convención humana, puesto que se dirige a la organización relativa a la administración de la ciudad, por lo tanto, según menciona Viola: 'El sostiene que en ese feliz estado no existiría el dominio despótico, es decir, no habría esclavitud, pero sí habría habido dominio político ya que, siendo el ser humano un animal social por naturaleza, siempre hay necesidad de que alguno lleve la obra de una pluralidad de personas hacia el bien común'46.

Debido a esto, se entiende lo mencionado por Santo Tomás cuando dice: 'La servidumbre entre los hombres es natural; pues algunos son, por naturaleza, siervos, como demuestra el Filósofo en I Pol. Pero las servidumbres pertenecen al derecho de gentes, como dice Isidoro. Luego el derecho de gentes es derecho natural. ${ }^{47}$ Efectivamente, en primera instancia pareciera ser que el Doctor Angélico incurre en una disyuntiva de carácter antropológico-moral, comprometiendo la dignidad y los derechos humanos, lo que parece no corresponder con los principios profesados por la fe cristiana. Pero esto se comprende, precisamente, debido a que Santo Tomás no considera la esclavitud desde un supuesto natural como se había dicho, sino que la aborda desde su utilidad o funcionalidad, por lo tanto, no hay punto de contradicción, ya que el Aquinate busca con esto probar que la servidumbre pertenece exclusivamente a un ordenamiento jurídico y de carácter humano, no propiciado por Dios, según explica el Doctor Angélico:

El hecho de que este hombre, al considerarlo en absoluto, sea más siervo que otro no tiene ninguna razón natural, sino sólo, ulteriormente, una utilidad consiguiente, en la medida en que es útil a aquél que sea dirigido por uno más sabio, y a éste que sea ayudado por aquél, como se dice en I Pol. Luego la servidumbre, que pertenece al derecho de gentes, es natural en el segundo modo, pero no en el primero. ${ }^{48}$

Entonces, se deja en claro que la servidumbre será entendida desde una concepción alusiva a su utilidad, gracias a esto, Santo Tomás de Aquino logra salvaguardar en parte la libertad y dignidad de la persona humana, puesto que el siervo no solamente gozará de muchos más beneficios que el esclavo en sentido aristotélico, sino que también, su trato deberá ser totalmente diferente, según afirma el Aquinate:

Y en este sentido es como se dice que es de derecho natural la posesión de los bienes en común y la libertad igual para todos, puesto que el reparto de los bienes y la servidumbre no fueron establecidas por la naturaleza, sino que fueron introducidas por la razón humana, que las consideró útiles para la vida humana. En esto, por tanto, la ley natural no cambia sino por adición. ${ }^{49}$

Por lo tanto, la servidumbre afectará solamente el cuerpo del siervo, pero jamás su alma, por ello, es que el siervo, independiente de su funcionalidad, permanece libre de manera intrínseca, según señala Santo Tomás:

La servidumbre de un hombre a otro afecta al cuerpo, no al alma, la cual permanece libre. Mas en el estado actual de esta vida, la gracia de Cristo nos libra de los defectos del alma, no de los del cuerpo, como nos consta por las palabras del Apóstol (Rom 7,25), el cual dice de sí mismo que con la mente sirve a la ley de Dios; con la carne a la ley del pecado. Y, en consecuencia, quienes son hechos hijos de Dios por la gracia están libres de la servidumbre espiritual del pecado, pero no de la servidumbre corporal por la que deben sumisión a sus señores temporales, como dice la Glosa sobre aquellas palabras de 1 Tim 6,1: Todos los siervos que están bajo el yugo de la servidumbre, etc. ${ }^{50}$

Asimismo, conviene señalar que el siervo debe cumplir con sus tareas y actividades serviles de manera adecuada y sin rebeldía injustificada, ya que esto es propio de la prudencia ${ }^{51}$ y docilidad ${ }^{52}$. Debido a que, el siervo se diferencia del libre en cuanto se encuentra bajo las órdenes de otro, por lo tanto, su voluntad se encuentra doblegada en disposición a su señor, ahora bien, a diferencia de Aristóteles, no hay una finalidad teleológica en ello, sino más bien, esto será parte del acuerdo establecido referente al derecho, debido a que será justo obedecer a otro que se encuentra en una posición más elevada, pero ante esto, también,

43. Martínez 2001, p.91

44. Cf. Argüello 2017, pp. 137-149

45. Tomás de Aquino, Sum. Theol., la, q. 96, a. 4, co

46. Viola 1995, p.478

47. Tomás de Aquino, Sum. Theol., II-llae, q. 57, a. 3, arg. 2

48. Tomás de Aquino, Sum. Theol., Il-llae, q. 57, a. 3, ad. 2

49. Tomás de Aquino, Sum. Theol., I-llae, q. 94, a.5, d. 3

50. Tomás de Aquino, Sum. Theol., II-llae, q. 104, a. 6, ad. 1

51. 'Para la teología clásica de la Iglesia, la prudencia es el modo que tiene el hombre de poseer, mediante sus decisiones y acciones, el bonum hominis o bien propiamente humano, el cual no es otra cosa que el bonum rationis o bien de la razón, o lo que viene a ser lo mismo: la verdad.' Pieper 2010, p.168.

52. Cf. Gilson 1978, p.506. Cf. Tomás de Aquino, Sum. Theol., II-Ilae, q. 49, a.3, co. 
debemos comprender que la diferencia principal subyace en la función relacional del siervo con respecto al amo, ya que siguiendo al Estagirita, Tomás de Aquino nos dirá que el siervo será considerado como parte del amo, tal como afirma el Aquinate:

El hijo, en cuanto hijo, es algo del padre; e igualmente, el siervo, en cuanto siervo, es algo del señor. Sin embargo, ambos, en la medida en que son considerados como unos hombres, son algo subsistente por sí mismo, diferente de los demás. Y por eso, en cuanto los dos son hombres, de alguna manera existe la justicia para éstos, y de ahí que se den también ciertas leyes sobre las cosas que son propias del padre para el hijo o del señor para el siervo. Pero, en cuanto uno y otro son algo del otro, según esto, falta aquí la perfecta razón de derecho o de lo justo ${ }^{53}$

De acuerdo con esto, Santo Tomás a diferencia de Aristóteles le concederá mayor autonomía al siervo, siendo subsistente por sí mismo, y pudiendo deliberar en una mayor medida sobre los asuntos relativos a la administración del hogar, sin embargo, igualmente será considerado como una posesión del amo, por ello, se destaca la sumisión y obediencia que se debe tener con respecto a la figura de autoridad, de ahí que, precisamente existan leyes diversas para complementar esto. Ahora, en el caso del siervo, su función versará exclusivamente en la administración de los bienes que el señor tenga en posesión, según señala el Doctor Angélico:

Según dice el Filósofo en I Polit., las relaciones entre las personas de la familia versan sobre los actos cotidianos, que se ordenan a llenar las necesidades de la vida. Estas necesidades son de dos órdenes: las unas, que miran a las necesidades del individuo y a la conservación de su vida. Para ello le sirven los bienes exteriores, de los cuales saca el alimento y el vestido, y lo demás necesario a la vida. Para la administración de estos bienes necesita el hombre de los siervos ${ }^{54}$

En consecuencia, Santo Tomás compartirá la opinión planteada por Aristóteles referente a la necesidad de los siervos para la adecuada administración de los bienes del amo, pero también es consciente de los derechos que deben poseer aquellos que se encuentran en condición de servidumbre, de ahí que afirme: 'primeramente, en lo que mira a los siervos, manda que se los trate con humanidad y que en el trabajo no se les agobie con faenas excesivas ${ }^{\prime 55}$. Por lo tanto, se presenta de manera explícita otra diferenciación primordial con respecto a la noción de esclavitud aristotélica, ya que, si bien el Estagirita igualmente concebía la esclavitud respetando ciertos derechos concernientes al esclavo, Santo Tomás de Aquino trascenderá aquella posición a un rango mayoritario, debido a que el trato caritativo y justo también es un mandato evangélico, y esto, logrará en definitiva que el siervo sea sujeto de derechos, lo que le permite no ser maltratado ni castigado de manera inhumana puesto que será parte esencial de la familia.

Finalmente, respecto del caso de la amistad entre el amo y el siervo, según dice Santo Tomás: 'Y así tampoco hay amistad del amo hacia el siervo en cuanto siervo, porque no tiene algo común, sino que todo el bien del siervo pertenece al señor, como todo el bien del instrumento pertenece al artífice. Pues el siervo es como un instrumento animado, y al revés, el instrumento es cuasi un siervo inanimado'56. Siguiendo la teoría aristotélica de la esclavitud, Santo Tomás comprende que el siervo en cuanto a su funcionalidad es en cierto sentido un instrumento animado, y por lo tanto, pareciera no poder aspirar a la amistad, ya que existe una desigualdad, sin embargo, al igual que el Estagirita aquello no priva que si pueda existir una amistad independiente de su funcionalidad, puesto que así lo deja en claro el Aquinate cuando afirma: 'Pues puede haber alguna amistad de cualquier hombre hacia todo hombre, en cuanto pueden tomar parte en alguna ley y en algún acuerdo, es decir, en algún pacto o compromiso. Y según este modo puede haber amistad del amo hacia el siervo en cuanto hombre'57.

\section{CONCLUSIÓN}

En primer lugar, se advierte que el pensamiento político de Santo Tomás de Aquino no se encuentra cabalmente registrado, por lo tanto, se dificulta sostener una postura al respecto de la servidumbre, de ahí que, se tienda a considerar su doctrina dentro de lo descrito en sus diferentes obras, principalmente: Summa Theologiae, Sententia libri Ethicorum, y Sententia Libri Politicorum. Si bien, en esta investigación se ha prescindido de muchas otras alusiones concernientes a su concepción política, como por ejemplo en el De Regno, se cumple el cometido de plantear ciertas similitudes y divergencias con respecto a la teoría esclavista de Aristóteles.

En segundo lugar, cabe señalar que la Edad Media goza de un contexto histórico-cultural totalmente diferente a la Edad Antigua, lo que implica una modificación social relevante, otorgándole otras cualidades que antes no se habían considerado, esto debido principalmente a la influencia cultural del cristianismo y al rol social de la Iglesia como agente promulgador de la fe. Por ello, Santo Tomás de Aquino concibe mayoritariamente la servidumbre desde una dimensión estrictamente teológica.

En tercer lugar, Santo Tomás de Aquino difiere de la noción de esclavitud aristotélica en ciertos aspectos, ya que el Aquinate no considerará el tema de la esclavitud como un supuesto natural, ni tampoco realizará una diferenciación morfológica de los cuerpos, de ahí que, para Santo Tomás la servidumbre sea mayormente un acuerdo racional, propio del Derecho de Gentes.

Finalmente, cabe destacar que Santo Tomás compartirá con el Estagirita la definición subyacente en la Política, en cuanto al siervo como cierta posesión animada, pero se añade una diferenciación importante, ya que el siervo igualmente goza de libertad intrínseca y cierta voluntad deliberativa para escoger sus funciones de mejor manera, por lo tanto, su finalidad será más noble que el esclavo en sentido aristotélico. Sin embargo, ambos serán necesarios para la administración correcta del hogar. De ahí que, también para Santo Tomás el siervo será entendido como un instrumento animado y activo, aunque independiente, pero igualmente sujeto a la voluntad del amo. En definitiva, Santo Tomás se preocupa más por el tema salvífico y teológico referente a la servidumbre. que por esclarecer su institución.

53. Tomás de Aquino, Sum. Theol., II-llae, q. 57, a. 4, ad. 2.

54. Tomás de Aquino, Sum. Theol., q. 105, a. 4, co.

55. Tomás de Aquino, Sum. Theol., I-llae, q.105, a. 4, co.

56. Tomás de Aquino, Sententia Ethic., Lib. VIII, L. XI, n.12.

57. Tomás de Aquino, Sententia Ethic., Lib. VIII, L. XI, n.13. 
- Aristóteles. Política. Introd., trad. y notas de Manuela García Valdés. Madrid, Gredos, 1988

- Aristóteles. Ética Nicomáquea. Introd. Emilio Lledó Íñigo, trad. y notas de Julio Pallí Bonet. Madrid, Gredos, 1993

- Aristóteles. Ética Eudemia. Introd. Emilio Lledó Íñigo, trad. y notas de Julio Pallí Bonet. Madrid, Gredos, 1993

- Ariza, Catalina. "Los objetos con alma: legitimidad de la esclavitud en el discurso de Aristóteles y Alonso de Sandoval. Una aproximación desde la construcción del cuerpo". Fronteras de la Historia, Instituto Colombiano de Antropología e Historia Bogotá, Colombia. núm. 10, pp. 139-170. (2005)

- Aeguello, Santiago. "El dominio en Tomás de Aquino y su sentido trascendental”, en Laura Corso de Estrada, María Jesús Soto-Bruna, Concepción Alonso del Real (Eds.), Figuras de la causalidad en la Edad Media y en el Renacimiento. Pamplona, EUNSA. No. 182, pp.137150. (2017)

- Brun, Jean. Aristóteles y el Liceo. Barcelona, Paidos. 1988

- Copleston, F.C. El Pensamiento de Santo Tomás. México. Fondo de Cultura Económica, 2014.

- Fraile, Guillermo O. P. Historia de la Filosofía II, filosofía judía y musulmana. Alta escolástica: desarrollo y decadencia. Madrid, B.A.C. 1975

- García, Miguel Ángel. "El problema de la esclavitud en Aristóteles", Pensamiento, vol. 64, no. 239, pp. 151-165, (2008)

- Gilson, Étienne. El Tomismo: Introducción a la Filosofía de Santo Tomás de Aquino. Pamplona, EUNSA, 1978.

- Gilson, Étienne. La Filosofía en la Edad Media: Desde los orígenes patrísticos hasta el fin del siglo XIV. Madrid, Gredos, 1995

- Leal, Yuliana. "El problema de la esclavitud en la política de Aristóteles", Revista Légein, N 4, enero - junio, pp. 7-23. (2007)

- Mauri, Margarita “La esclavitud natural: una revisión de las tesis de Aristóteles". Ideas y Valores, 65, no.162, pp. 161-187. (2016).

- Manser, G.M. La esencia del tomismo. Madrid, Consejo Superior de Investigaciones Científicas, 1947.

- Martínez, Jorge. La política en Aristóteles y en Tomás de Aquino. Cuadernos de Anuario Filosófico n 122, Serie Universitaria, Pamplona, España. 2001

- Mirón, María Dolores. “Oikos y oikonomia: El análisis de las unidades domésticas de producción y reproducción en el estudio de la Economía antigua". Gerión, vol. 22, no. 1 pp. 61-79, (2004)

- Moreau, Joseph. Aristóteles y su escuela. Buenos Aires, EUDEBA, 1972.

- Neira, Carmenza. "Comentario a la Política de Aristóteles". Cuadernos de filosofía latinoamericana, vol. 26, no. 93, pp. 7-18, (2005)

- Paul J. Cornish, "Marriage, Slavery, and Natural Rights in the Political Thought of Aquinas", The Review of Politics, Vol. 60, No. 3 pp.545561, (1998).

- Pieper, Josef. Las virtudes fundamentales. Madrid, Rialp, 2010.

- Ross, W.D. Aristóteles. Buenos Aires, Charcas. 1957

- Reale, Giovani. Introducción a Aristóteles. Barcelona, Herder. 1985

- Rassam, Joseph. Introducción a la filosofía de Santo Tomás de Aquino. Madrid, Rialp, 1980.

- Santo Tomás de Aquino. Suma de teología I, tomo I. Madrid, B.A.C., 2001

- Suma de teología I-Il, tomo II. Madrid, B.A.C., 1989

- Suma de teología II-II (a), tomo III. Madrid, B.A.C., 1990

- Suma de teología II-II (b), tomo IV. Madrid, B.A.C., 1994 
- Suma de teología III, tomo V. Madrid, B.A.C., 1994

- Comentario a la Ética a Nicómaco de Aristóteles. Trad. de Ana Mallea, estudio preliminar y notas de Celina A. Lértona. Pamplona, EUNSA, 2001.

- Velázquez, Héctor. “En torno a la servidumbre natural en Tomas de Aquino", Tópicos, 8, pp.69-91, (1995).

- Vigo, Alejandro G. Aristóteles Una introducción. Santiago, Instituto de Estudios de la Sociedad. 2007

- Viola, Francesco. "La politica nella Somma Teologica", in "Sacra Doctrina", 34, n.6, pp.585-603, (1989); publicación en lengua española (trad. Di V.Bellver) con el título: "La Política en la Suma Teológica", in J. Ballesteros et al. (a cura), Justicia, Solidaridad, Paz, Valencia, pp.469-479. (1995) 